REVIEW

\title{
Appropriate and effective management of rheumatoid arthritis
}

\author{
F C Breedveld, J R Kalden
}

Ann Rheum Dis 2004;63:627-633. doi: 10.1136/ard.2003.011395

Early referral (at $<3$ months) and early DMARD treatment enable the course of RA to be changed. Once the disease has become aggressive it is much harder to treat and improvements will not be as great as they would have been with earlier treatment. The latest strategies and treatments enable remission to be achieved in many more patients than formerly.

See end of article for authors' affiliations

......................

Correspondence to: Professor F C Breedveld, Department of Rheumatology, Leiden University Medical Centre, 2300 RC Leiden, The Netherlands; F.C. Breedveld@lumc.nl

Accepted 7 February 2004 ........................
With the availability of new treatments for rheumatoid arthritis (RA) and increasing expectations for patient outcomes, the treatment paradigm for patients has changed dramatically over the past few years. As patients and their physicians are presented with more treatment options, it is increasingly important that rheumatologists continue to reach a consensus on the appropriate and effective management of RA and implement treatment guidelines to the full benefit of patients.

There are a greater number of, and better, RA management tools and processes than ever before. Rheumatologists know more about the pathogenesis, course, and progression of RA, and have improved ways of measuring disease activity. There are even more traditional and biological disease modifying antirheumatic drugs (DMARDs) in the treatment armamentarium and many more combinations in which to use them. There are indications that these therapeutic agents should be used in the early "window of opportunity" to help patients with RA achieve long term and sustained improvement. In addition, international and national guidelines are continually and intensively being refined to encourage early and more aggressive intervention in patients with RA. These tools and processes, in turn, permit rheumatologists to set higher goals for patients. The latest strategies and treatment options open the way to bring many patients with RA into low disease activity and remission.

\section{ECONOMIC BURDEN OF RA}

Despite the use of traditional treatments, RA still progresses linearly over time, leading to premature mortality, increased morbidity, significant decrease in quality of life (pain, fatigue,

\section{RA DISEASE MANAGEMENT: A SHIFTING PARADIGM}

depression), and functional and work disability. ${ }^{12}$ Several patient outcome measures-the Health Assessment Questionnaire (HAQ), Disease Activity Score (DAS), and Short Form36-are essential to quantifying and predicting the economic impact of the disease. Of these, the HAQ is very predictive of functional and work disability, cost of disease treatment, and joint replacement surgeries..$^{3-6}$

The economic burden of RA can be dichotomised into direct healthcare costs and indirect costs, including loss of productivity. Annual healthcare costs correlate well with degree of disability. For example, a North American study by Fries et al showed that the most severe disease expression of RA has the greatest costs. Patients with an HAQ score of 3 accounted for three times the expenditures of patients with an HAQ score of 1 (more than $\$ 45000$ per patient over five years $v$ approximately $\$ 15000) .{ }^{5}$ More than $50 \%$ of the money spent goes to hospital admissions. However, these hospital admission dollars are spent on only $10 \%$ of all patients with RA. ${ }^{6}$ Saving costs in hospital admissions would have a big impact on making more resources available for a significantly greater number of patients.

\section{"Savings on high hospital costs, which benefit only a few patients, would allow more patients to be treated"}

Indirect productivity costs are primarily related to employment (change of job, reduced work, loss of job, early retirement, and decreased income). In these areas, RA is much more of an economic burden than osteoarthritis. ${ }^{7}$ Treatment of RA has demonstrated an impact on long term outcomes and mortality. A 10 year prospective follow up of patients receiving methotrexate (MTX) showed that MTX non-responders have a 5.6-fold increase in mortality compared with the general population, ${ }^{8}$ and, in a study by Choi et al, patients with severe RA who were treated with MTX showed a $60 \%$ reduction in mortality. ${ }^{9}$ Increasingly successful treatments, such as biological agents, are expected to reduce mortality further.

\footnotetext{
Abbreviations: ACR, American College of Rheumatology; CTLA-4, cytotoxic T lymphocyte antigen-4; DAS, disease activity score; DMARDs, disease modifying antirheumatic drugs; $\mathrm{HAQ}$, Health Assessment Questionnaire; IL, interleukin; MMP, matrix metalloproteinase; MTX, methotrexate; NSAIDs, nonsteroidal anti-inflammatory drugs; RA, rheumatoid arthritis; TNF, tumour necrosis factor
} 


\section{NEW INSIGHTS INTO RA PATHOGENESIS}

The most characteristic feature of RA is synovial proliferation, which ultimately leads to joint destruction. Part of this process, cartilage destruction, is mediated by several extracellular factors, including matrix degrading enzymes such as lysosomal cathepsins, matrix metalloproteinases (MMPs), and membrane-type MMPs. ${ }^{10}$ Because it is uncertain which of these factors contributes most significantly to joint inflammation and destruction, and several have other important physiological functions, the development of agents that specifically inhibit these inflammatory elements simultaneously has, until now, not been successful.

The aetiology of RA can be succinctly but non-specifically characterised as the interaction of a genetically susceptible host with an unidentified, external inflammatory stimulus. ${ }^{11}$ Because the cause and initiating factors of RA are unknown, RA-specific treatments are not under investigation at this time. Current treatments target a variety of immune processes and are based on recent insights into RA pathophysiology, which are expanding and evolving with our rapidly increasing understanding of the relationships between cell biology and inflammation. Knowledge of the mechanisms driving tissue destruction in RA has led to the evaluation of several therapeutic principles and new biological agents that target immune processes. ${ }^{12}$ Table 1 summarises these targets and therapeutic approaches.

\section{"Cytotoxic T lymphocyte antigen-4 is a potential blocker of T cell activity"}

A few of these target therapeutic agents are interesting and warrant further discussion. CD28 is a glycoprotein identified as providing non-antigen driven costimulatory signals to complement $\mathrm{T}$ cell receptor driven signals during $\mathrm{T}$ cell responses, leading to optimal $\mathrm{T}$ cell activation. Cytotoxic $\mathrm{T}$ lymphocyte antigen-4 (CTLA-4) is a homologue of CD28 expressed by activated $\mathrm{T}$ cells. A soluble fusion protein composed of a CTLA-4 molecule linked to the fixed chain or Fc portion of human immunoglobulin antibody $\operatorname{IgGl}$ is being evaluated for its ability to block the interaction of CD80/CD86 with CD28, as a way of inhibiting T cell activation. CTLA-4 may not only inhibit activation of proinflammatory Thl mediated autoimmune cells, such as are found in RA, but also prevent the differentiation of immunomodulatory Th2

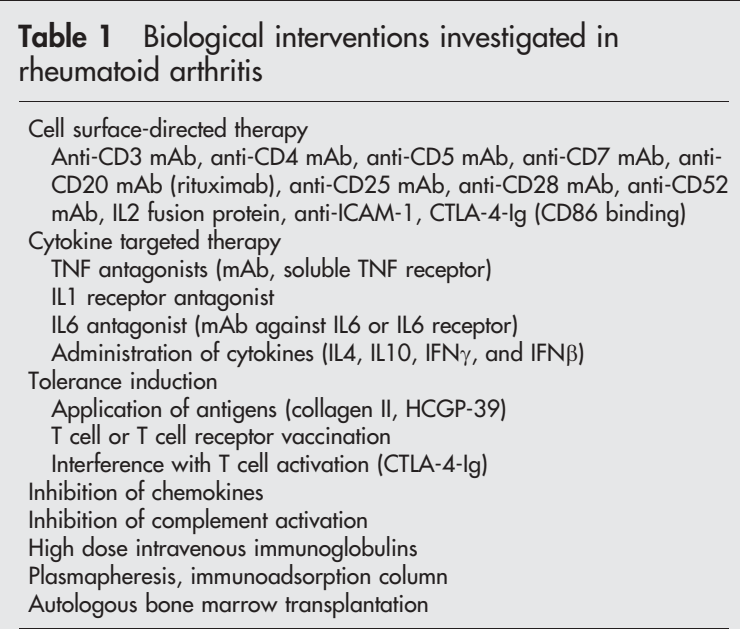

$\mathrm{mAb}$, monoclonal antibody; IL, interleukin; ICAM, intracellular adhesion molecule; CTLA-4, cytotoxic T lymphocyte antigen-4; Ig, immunoglobulin; TNF, tumour necrosis factor; IFN, interferon. Adapted with permission from Breedveld FC. ${ }^{12}$ effectors. ${ }^{12}$ Randomised, controlled trials of CTLA-4-Ig in RA are underway.

Although RA is predominantly a T cell mediated disease, B cell depletion therapy is another new approach that is proving viable. Rituximab, approved to treat the most common type of low grade non-Hodgkin's lymphoma, is a humanised monoclonal antibody directed against CD20, a B cell restricted differentiation antigen. ${ }^{12}$ Recent findings indicate that $\mathrm{B}$ cell depletion in patients with RA has a selective effect on autoantibody concentrations. Relapse of $\mathrm{RA}$ is associated with rises in specific autoantibody concentrations, but not necessarily an increase in B cells. ${ }^{13}$

Described in detail during the past 10 years, tumour necrosis factor (TNF) is a central cytokine in RA pathogenesis. It participates in the early stages of the inflammatory cascade promoting downstream mediators, ultimately leading to bone and joint destruction. TNF stimulates the synthesis of other proinflammatory cytokines, including interleukin (IL)1, IL6, IL8, and granulocyte macrophagecolony stimulating factor; and induces endothelial cells to express adhesion molecules that attract leucocytes into affected joints. It also stimulates the production of MMPs by synovial macrophages, fibroblasts, osteoclasts, and chondrocytes; and suppresses the neosynthesis of cartilage proteoglycans. ${ }^{14} 15$ Produced mainly by monocytes and macrophages, TNF influences all aspects of the disease, and is a major contributor to the pathological and destructive changes that occur in patients with RA. ${ }^{16}{ }^{17}$

The inflammatory cytokine pathways can be inhibited through several therapeutic approaches. One is direct cytokine neutralisation. For TNF, this includes either monoclonal antibodies (adalimumab and infliximab, which are specific to TNF) or TNF soluble receptor fusion constructs (etanercept, which binds to both TNF and lymphotoxin). Using this approach, TNF antagonists directly bind to TNF before it can bind to its cell surface receptors. Another approach is receptor blockade, which has been used to inhibit ILl through anakinra, a recombinant ILl receptor antagonist, which directly blocks ILl cell receptors.

Another approach is indirect inhibition by blocking "upstream" cytokines that have a role in stimulating production of the cytokine of interest. There is evidence that inhibition of TNF and ILl, in effect, block paracrine and autocrine effects of those cytokines. This may be one of the mechanisms through which inhibition of other cytokines, such as IL6 (for example, with a monoclonal antibody against the IL6 receptor), mediates their effects. Another approach is the inhibition of TNF cleaving enzyme, an enzyme that cleaves TNF from the cell surface. Inhibition of TNF cleaving enzyme would prevent TNF from becoming a soluble cytokine. Although the last two approaches may hold future promise, the three anti-TNF agents-infliximab, a chimeric monoclonal antibody; etanercept, a soluble receptor construct; and adalimumab, a fully human monoclonal antibody-are currently available and have been shown to be safe and effective in the treatment of RA.

\section{"Retroviral sequences may be responsible for the activa- tion of synovial fibroblasts"}

In addition to cytokine mediated mechanisms, a new pathway has been proposed to further explain the activation of synovial fibroblasts. Since recognising through mouse models that fibroblasts may become activated without the interactions of macrophages and $\mathrm{T}$ cells, researchers have been searching for alternative fibroblast activators. They suggested that retroviral sequences might be responsible for this phenomenon. 
The human retrotransposon or Ll—expressed at the site of invasion with the synovial cells invading cartilage-proved to be a viable explanation. Because Ll was found at the site of invasion, scientists further investigated if it would independently engage the p38 intracellular signalling pathway in parallel with the well known p38 kinase activation, which is driven by the cytokine-to-cytokine receptor interactions of TNF, ILl, and other cytokines. Work by Gay et al verified the presence of $\mathrm{p} 38 \delta$, a cytokine independent pathway that also results in the production of matrix degrading enzymes such as MMP. Possibly, these two pathways complement each other, and one or the other may be more prevalent in different patients. Such a circumstance would plausibly explain the varying degrees to which different patients respond to biological agents.

\section{IMPORTANCE OF EARLY AND AGGRESSIVE RA TREATMENT}

Historically, DMARDs have been used cautiously in patients with RA to avoid toxicities linked to high dosing or combination therapy. However, several randomised, controlled trials demonstrate that an early and aggressive approach to treatment is essential for controlling disease activity effectively and achieving optimal results. Early and aggressive therapy means using the best treatments available, and using them early to prevent irreversible disease progression. Early and aggressive treatment includes one or more DMARDs at effective doses-doses reached early in the treatment process. In addition, aggressive treatment requires stringent patient monitoring to achieve maximum therapeutic efficacy with minimum toxicity.

Defining "early" is an important matter. By survey, more than two thirds of European rheumatologists consider disease duration of 3 months or less as "early RA." However, these same surveyed rheumatologists said that $50 \%$ of their patients are referred after 6 months of disease. ${ }^{18}$ Many patients are not seen until up to 1 year or more, and data from Emery et al indicate that $60 \%$ of patients have erosive disease by 1 year. Other data suggest that approximately $75 \%$ of patients have joint erosions by the 2 year mark, and $25 \%$ have erosions as early as 3 months. In contrast, a study by Machold et al on time to initiation of traditional DMARDs indicates that by 3-4.5 months from the onset of symptoms $70 \%$ of Austrian patients are receiving DMARDs. Over the course of 1 year, joint erosions had increased from $10 \%$ to $25 \%$ of patients, despite DMARD treatment started within the first 3-4.5 months. ${ }^{19}$

\section{"Early aggressive treatment with DMARDs is needed to achieve the greatest effect on long term outcome"}

Lard et al compared patients whose treatment started within 15 days of referral with patients treated after a delay of about 4 months. After 2 years, median total Sharp scores for the delayed group were approximately four times higher than for the early treatment group. Moreover, in patients in the early treatment group, radiographic damage stopped progressing. ${ }^{20}$ Nell et al compared the DAS28 scores over time of patients with very early RA ( $<3$ months) with those with late-early RA (6 months-3 years). Patients in both groups had baseline DAS28 scores in the high disease activity range. Although both groups had statistically significant improvements over time, the late-early group reached a plateau in the moderate activity range and the very early group improved into the low activity range. ${ }^{21}$ The largest difference in relative improvements occurred during the first year. During years 2 and 3, the improvement trend lines ran in parallel. The study by Lard et al and another by Emery et al show that giving early treatment with traditional DMARDs improves long term outcomes and quality of life more than delaying treatment by as little as 3 months. ${ }^{20} 22$

In support of early and aggressive treatment, Emery and colleagues developed an early referral algorithm for newly diagnosed RA. Patients should be referred to rheumatologists upon the mere clinical suspicion of RA, which is supported by the presence of any of the following: three or more swollen joints; metatarsophalangeal/metacarpophalangeal involvement by squeeze test; and morning stiffness of 30 minutes or more. ${ }^{22}$

Clinical evidence showing that early treatment is more beneficial than later treatment is further supported by data on the immediate and sustained reduction of $\mathrm{C}$ reactive protein and erythrocyte sedimentation rate values during DMARD treatment. These reductions indicate that the first DMARD used appears to be more effective than subsequent DMARDs, regardless of the type of initial DMARD used. ${ }^{23}$ This is also reflected in retention rates for the first DMARD used compared with subsequent DMARDs, which shows that patients continue to receive the first DMARDs for almost twice as long as their fourth and subsequent DMARDs. ${ }^{23}$

Evidence also indicates that aggressive treatment can be better than more conservative treatment. Data on MTX use show that approximately $60 \%$ of patients receiving high dose MTX (>12.5 mg/week) are still taking the drug after 6 years, whereas fewer than $37 \%$ receiving low doses are still taking the drug after the same time period. ${ }^{24}$ One very interesting trial is the Combinatietherapie Bij Reumatoide Artritis (COBRA) trial in early RA, which compared sulfasalazine monotherapy with sulfasalazine combination therapy with prednisolone and MTX in a step-down approach. During this trial, prednisolone and MTX were sequentially discontinued over time. After 56 weeks of treatment, results for a pooled index of outcomes were better in the patients who underwent the step-down approach. The results of this trial indicate that this aggressive approach in patients with early RA improves patients' outcomes. ${ }^{25}$

Trial data show that patients who receive biological agents early in RA achieve greater decreases in the signs and symptoms of the disease than patients taking MTX. At 52 weeks in a trial of patients with early RA taking etanercept $v$ placebo, $72 \%$ of patients taking $25 \mathrm{mg}$ achieved American College of Rheumatology (ACR) $20 v 65 \%$ for MTX alone, $49 \%$ achieved ACR50 $\vee 43 \%$ for MTX alone, and 25\% achieved ACR70 $v 22 \%$ for MTX alone. ${ }^{26}$ Other trial data show that patients have significantly greater inhibition of radiographic progression when the biological agents are started earlier in the disease process. ${ }^{27}$

Data on early and aggressive treatment suggest there is a "window of opportunity" very early in the disease process$<3$ months of disease duration. Early referral and early DMARD treatment provide a unique opportunity to change the course of RA. The somewhat small but important window may exist between the start of symptoms and the start of radiographic damage. This means that once the disease has become aggressive, it is much harder to treat, and improvements will probably never be as great as they would have been with earlier treatment. The challenges rheumatologists face are to get patients referred, diagnosed, and receiving DMARD treatment rapidly (fig l).

\section{TRADITIONAL DMARDs AND THE ROLE OF BIOLOGICAL AGENTS}

With traditional DMARDs, rheumatologists and other treating physicians use two main treatment approachesmonotherapy and combination therapy. Monotherapy is a first line treatment approach and usually involves sequential 


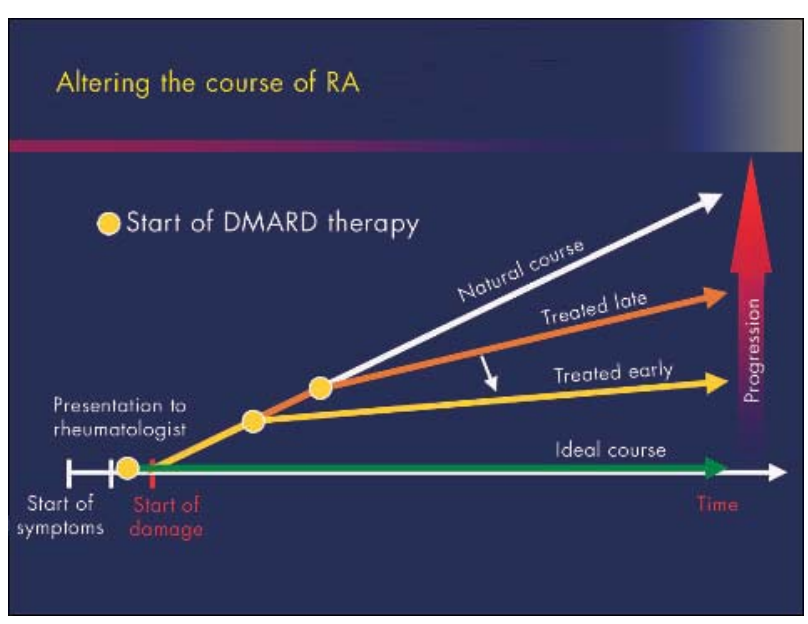

Figure 1 Altering the course of RA. Reproduced with permission of the copyright holder, J Smolen.

monotherapy. Thus, treatment of patients is started with one DMARD, and, if this is not efficacious or is toxic, that DMARD is discontinued and another started; the process is repeated as necessary. Sulfasalazine, hydroxychloroquine, and MTX are the most commonly used traditional DMARDs, and MTX, in particular, has been used most effectively in these patients. ${ }^{28} 29$ Corticosteroids have been an important but controversial RA treatment. ${ }^{30}$ They have dramatic, short term anti-inflammatory properties, but at high doses, or given over a long period, may have devastating side effects. Corticosteroids can be effective in helping patients to manage pain and functional disability. In studies of patients with early, active RA, they have helped, in combination with other treatments, to substantially reduce the rate of radiologically detected disease progression. However, most studies, and 50 years of use, show that corticosteroids are inadequate as sole treatment for RA. ${ }^{30}$

Combination therapy can be used in the following different ways: (a) a continuous approach, in which the rheumatologist prescribes two or more DMARDs with the intention of continuing all the DMARDs involved; $(b)$ a step-up approach, in which the rheumatologist begins with the conventional monotherapy approach and adds subsequent DMARDs if adequate efficacy is not achieved; and (c) a step-down approach, the most aggressive of the three, in which the rheumatologist initiates several DMARDs at the onset, with the intention of discontinuing the most toxic or the most expensive, once goals are achieved. Research results are controversial. However, much of the data suggest that combination therapy is more efficacious than monotherapy, and not necessarily more toxic. ${ }^{25} 31$

When efficacy is examined, traditional DMARDs are found to have several benefits. They improve the signs and symptoms of RA, reduce inflammation, improve functional/ disability status in comparison with non-steroidal antiinflammatory drugs (NSAIDs) in early RA, slow down radiographic progression, provide dosing flexibility, and have well studied and quantified toxicity and drug interaction profiles. However, they also have several important limitations. They have a delayed onset of action (1-6 months in most cases); some have less proved effectiveness on radiographic disease progression and health related quality of life; require close monitoring because of multiple toxicities; provide for difficult and complex dosing regimens; provide limited long term sustainability; and seldom yield treatmentfree remissions. Thus, $50 \%$ of patients taking MTX discontinue because of inefficacy or toxicity after 5 years. ${ }^{24}$
Arthroplasties, including total joint replacements, have been reported in $17-25 \%$ of patients with RA, of whom, $75 \%$ had received DMARD treatment. ${ }^{32} 33$

The biological DMARDs have arisen out of the need to deal with these limitations. Over the past 70+ years, RA management has evolved from very cautious, very modestly effective treatment, based on a reactive approach and almost solely on symptom relief, to a proactive, early, and aggressive treatment approach, designed to be comprehensive and prevent the devastating effects of the disease. In the 1930s and 40s, gold, penicillamine, and hydroxychloroquine dominated, followed by steroids in the 50s and NSAIDs in the 60s, with limited success. Sulfasalazine made its debut in the 60s, MTX in the 80s, and combination therapy with traditional DMARDs in the early 90s. Most of these treatments had limited and unpredictable efficacy, relying heavily on affecting the outward manifestations of inflammation rather than underlying disease activity.

Without many of the limitations associated with traditional DMARDs, the first biological agents were approved for the treatment of patients with RA in 1998 and provided a new therapeutic standard. TNF antagonists, in particular, provide a predictable response for both efficacy and safety, either in combination with MTX, in combination with standard care, or as monotherapy. For example, data reported by Weinblatt et al established the ability of etanercept with MTX to reduce the signs and symptoms of RA. The percentages of patients at $25 \mathrm{mg}$ etanercept twice weekly to achieve ACR responses at 6 months were $71 \%$ for ACR20, $39 \%$ for ACR50, and 15\% for ACR70. ${ }^{34}$ In the Anti-TNF Trial in Rheumatoid Arthritis with Concomitant Therapy or ATTRACT trial, the percentages of patients at 3 and $10 \mathrm{mg} / \mathrm{kg}$ infliximab every 8 weeks plus MTX who achieved ACR responses at 54 weeks were $42 \%$ and $59 \%$ for ACR20, $21 \%$ and $39 \%$ for ACR50, and $10 \%$ and $25 \%$ for ACR70, respectively. ${ }^{35}$ In the Anti-TNF Research Study Program of the Monoclonal Antibody Adalimumab in Rheumatoid Arthritis (ARMADA) trial, the percentages of patients at $40 \mathrm{mg}$ adalimumab every other week in combination with MTX to achieve ACR responses at 6 months were $67 \%$ for ACR20, 55\% for ACR50, and 27\% for ACR70. ${ }^{36}$ Therefore, in combination trials with MTX, TNF antagonists generally showed a similar response pattern, a pattern informally referred to as the " $60-40-20$ " rule, with about $60 \%$ of patients reaching ACR20, 40\% reaching ACR50, and 20\% reaching ACR70.34-36 Results obtained with anakinra in combination with MTX are lower, perhaps a result of the difficulty of blocking the ILl pathway with a receptor antagonist as well as anakinra's relatively short half life of 4-6 hours. ${ }^{37}$

The limitations of traditional DMARDs such as MTX and leflunomide include toxicities, especially hepatotoxicities. For patients eligible for treatment with TNF antagonists, these effects can be overcome by using the TNF antagonists as monotherapy. This approach avoids compounding toxicities through combination therapy and gives patients intolerant to MTX or other traditional DMARDs more options. The two monotherapy trials for etanercept in early and established RA yielded a significantly higher response than placebo. ${ }^{26}{ }^{38}$ In addition, despite patients' very significant disease severity at onset and nonresponse to previous MTX treatment, ACR response rates in a monotherapy trial for adalimumab were statistically significantly higher than for placebo. ${ }^{39}$

The TNF antagonists each share a rapid onset of actionoften as early as 1 or 2 weeks. Infliximab demonstrated that more than half of ultimate responders attaining ACR20 did so by their first evaluations at week 2, and more than $90 \%$ at the 6 week evaluation. ${ }^{40}$ The ARMADA trial demonstrated that 
$25 \%$ of patients receiving $40 \mathrm{mg}$ adalimumab every other week achieved an ACR20 response in the first week of treatment, and about $75 \%$ of the patients who would respond did so by 4 weeks. ${ }^{36}$ Comparably, patients who responded to monotherapy in the adalimumab monotherapy study also did so by 4 weeks. ${ }^{39}$ Similarly quick responses have been seen for etanercept. ${ }^{26} 3438$

Several long term studies support the sustained response of TNF antagonists past 5 years. An open label extension study of etanercept demonstrated response durability at 5 years. At that time, mean tender joint count was less than $5 .{ }^{41}$ Sustained response to 4 years was also demonstrated by a long term rollover study of adalimumab with MTX in patients with partial response to MTX. In this study, one year ACR20 scores were sustained to 4 years, and ACR50 and ACR70 scores continued to rise. Likewise, one year DAS28 improvements were sustained to 4 years. ${ }^{42}$ Similar long term results have been seen for infliximab. Technical issues about the judgment of the results of open label extension studies were recently discussed. ${ }^{43}$

With respect to health related quality of life, the ATTRACT trial showed a highly significant median improvement from baseline to week 54 in HAQ scores $(0.1$ for the patients taking placebo and MTX $v 0.4$ for patients taking infliximab and MTX, p $<0.001)^{44}$ (with a change of 0.22 or more being clinically important). ${ }^{45}$ In addition, trials for etanercept and adalimumab showed that patients with partial response to MTX receive a clear clinical benefit from adding a TNF antagonist to their regimens. Moreover, improvement in physical function and health related quality of life were demonstrated through improvements well above the minimum clinically important differences in HAQ scores; and Short Form-36 physical component summary, pain, and vitality scores across several of the pivotal trials for infliximab, etanercept, and adalimumab..$^{35} 363846$

TNF antagonists routinely inhibit radiographic progression. Infliximab and adalimumab, for example, yielded significantly smaller mean changes from baseline in total Sharp scores $v$ placebo after 1 year in patients with significant disease ( 1.3 for infliximab $3 \mathrm{mg} / \mathrm{kg}$ every 8 weeks $v 7$ for placebo, $\mathrm{p}<0.001$; and 0.1 for adalimumab $40 \mathrm{mg}$ every other week $v 2.7$ for placebo, $\mathrm{p} \leqslant 0.001) .{ }^{35} 4748$ In addition, mean changes from baseline for joint erosions and joint space narrowing $v$ placebo were also significantly smaller (joint erosions: 0.2 for infliximab $3 \mathrm{mg} / \mathrm{kg}$ every 8 weeks $v 4$ for placebo, $\mathrm{p}<0.00 \mathrm{l}$; and 0 for adalimumab $40 \mathrm{mg}$ every other week $v 1.7$ for placebo, $\mathrm{p} \leqslant 0.001$; joint space narrowing: 1.1 for infliximab $3 \mathrm{mg} / \mathrm{kg}$ every 8 weeks $v 2.9$ for placebo, $\mathrm{p}<0.00 \mathrm{l}$; and 0.1 for adalimumab $40 \mathrm{mg}$ every other week $v$ 1.1 for placebo, $\mathrm{p} \leqslant 0.001) .^{35}{ }^{48}$ In the Early Rheumatoid Arthritis trial of etanercept, the mean change in total Sharp scores after 2 years was 1.3 for the $25 \mathrm{mg}$ group $v 3.2$ for placebo, $\mathrm{p}=0.00 \mathrm{l}$; and 0.7 for the $25 \mathrm{mg}$ group $v 1.9$ for placebo for joint erosions, $\mathrm{p}=0.001 .{ }^{26}$ At week 52 the progression of erosion scores was respectively 0.47 and 1.03 $(\mathrm{p}=0.002)$.

TNF antagonists are generally safe and well tolerated. Rare but important events have been reported for each. These include serious and opportunistic infections, including tuberculosis; malignancies; demyelinating disorders; administration reactions; congestive heart failure; autoantibody formation; and lupus-like syndrome. ${ }^{49}$ Although they have some safety considerations, TNF antagonists overcome several of the limitations of traditional DMARDs. They have a rapid onset of action, provide consistent responses, improve quality of life, significantly inhibit radiographic progression, provide sustained efficacy, and are well tolerated. Their benefit/risk ratio makes them a useful addition to the therapeutic armamentarium of the rheumatologist.

\section{RA TREATMENT GUIDELINES AND THE GOAL OF CLINICAL PRACTICE TODAY: REMISSION}

National guidelines and international and European consensus statements are important for several reasons. They standardise management and therapeutic approaches, consider all available evidence of positive and negative drug effects, summarise documentation of efficacy and toxicity, and consider cost effectiveness ratios.

The international consensus statement, revised in May 2002, states that "TNF antagonists are recommended for the treatment of active RA after an adequate trial of another effective DMARD, of which methotrexate (MTX) is a commonly used example." ${ }^{\prime 50}$ They may be added to preexisting treatment or replace previous DMARDs or other biological agents. They are effective in MTX-naïve patients, and may be considered first line when other DMARDs are contraindicated. They should lead to significant, documentable improvement within 12 weeks, or be discontinued, and should not be started or should be discontinued under certain conditions.

Criteria to consider when selecting which biological agent to use may include: target selection-TNF antagonist $v$ ILl antagonist; binding affinity; half life; patient preferences for administration; and formulation (ready to use liquid preparation $v$ lyophilised formulation, necessitating reconstitution).

Today, a significant proportion of patients with mild, moderate, or severe RA receive NSAIDs and steroids before starting aggressive DMARD treatment. Many patients with moderate or severe disease receive suboptimal doses of traditional DMARDs as monotherapy or combination therapy. Biological agents are primarily being used only in patients with severe disease. However, the guidelines recommend that all patients with mild to moderate disease should be treated with traditional DMARDs, and those with moderate disease should also be considered for biological therapy.

Historical RA management entailed controlling inflammation through conservative treatment with NSAIDs. DMARDs were withheld until there was clear evidence of joint damage and were added individually in slow succession as disease progressed. This approach yielded few long term remissions, and unsatisfactory outcomes. Current RA management, still evolving, includes early, aggressive treatment-with the goals of minimising long term joint damage and achieving remission. DMARD combinations including biological agents are used to a much greater degree.

Well defined guidelines, treatment and referral algorithms, and research on the safety and efficacy of traditional DMARDs and biological agents abound. Yet, the use of traditional DMARDs is still suboptimal. After decades of research, rheumatologists have better tools to diagnose and treat RA and measure disease activity, including a greater number of traditional DMARDs; biological agents, a new therapeutic standard; and increasingly sensitive laboratory markers, radiographic measurement tools, and patientoutcome measures. Rheumatologists also have better processes available through which to approach treatment. They have accumulated considerable evidence on early and aggressive treatment and guidelines that reflect this evidence to help direct therapeutic courses of action. With these new and better tools and processes, they can set a very high but realistic goal for their patients-remission (fig 2).

\section{ACKNOWLEDGEMENTS}

The concepts of RA management reviewed in this paper were discussed during an international scientific forum supported by an unrestricted educational grant from Abbott Laboratories.

We gratefully thank the following members for their contributions: Dr Christian Antoni, University Erlangen-Nürnberg, Germany, 


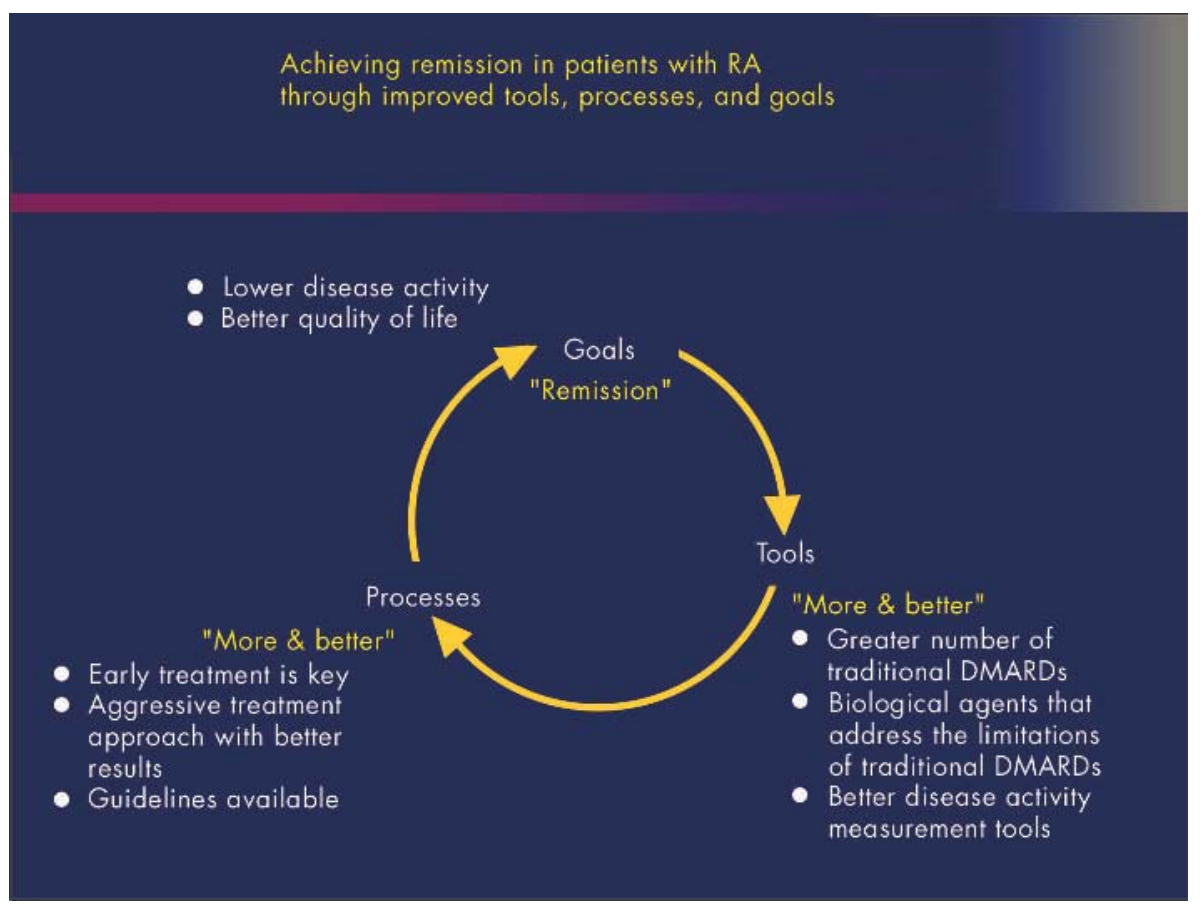

Figure 2 Achieving remission in patients with RA through improved tools, processes, and goals. Reproduced with permission of the copyright holder, J Smolen.
"Epidemiology, clinical course, and burden of disease"; Professor Maxime Dougados, MD, René Descartes University, Cochin Hospital, Paris, France, "Traditional therapies"; Professor Paul Emery, MD, University of Leeds, United Kingdom, "Efficacy profile of adalimumab"; Professor Steffen Gay, MD, University Hospital, Zurich, Switzerland, "Pathophysiology"; Professor Edward Keystone, MD, University of Toronto, Mount Sinai Hospital, Toronto, Canada, "AntiTNF biologics: new therapeutic standard"; Professor Josef Smolen, MD, University of Vienna, Lainz Hospital, Vienna, Austria, "Early, aggressive RA therapy"; and Professor Leo van de Putte, MD, University Hospital, Nijmegen, The Netherlands, "Overview of TNF antagonists."

\section{Authors' affiliations}

F C Breedveld, Department of Rheumatology, Leiden University Medical Centre, Leiden, The Netherlands

J R Kalden, Department of Internal Medicine III, Friedrich-Alexander University, Erlangen, Germany

\section{REFERENCES}

1 Wolfe F, Hawley DJ. The long-term outcomes of rheumatoid arthritis: work disability: a prospective 18-year study of 823 patients. J Rheumatol 1998;25:2108-17.

2 Wolfe F, Mitchell DM, Sibley JT, Fries JF, Bloch DA, Williams CA, et al. The mortality of rheumatoid arthritis. Arthritis Rheum 1994;37:481-94.

3 Pincus T, Brooks RH, Callahan LF. Prediction of long-term mortality in patients with rheumatoid arthritis according to simple questionnaire and joint count measures. Ann Intern Med 1994; 120:26-34.

4 Fries JF, Williams CA, Morfeld D, Singh G, Sibley J. Reduction in long-term disability in patients with rheumatoid arthritis by disease-modifying antirheumatic drug-based treatment strategies. Arthritis Rheum 1996:39:616-22

5 Fries JF. Safety, cost and effectiveness issues with disease-modifying antirheumatic drugs in rheumatoid arthritis. Ann Rheum Dis 1999;58(suppl I):I86-9.

6 Yelin E, Wanke LA. An assessment of the annual and long-term direct costs of rheumatoid arthritis: the impact of poor function and functional decline. Arthritis Rheum 1999;42:1209-18.

7 Gabriel SE, Crowson CS, Campion ME, O'Fallon WM. Indirect and nonmedical costs among people with rheumatoid arthritis and osteoarthritis compared with nonarthritic controls. J Rheumatol 1997;24:43-8.

8 Krause D, Schleusser B, Herborn G, Rau R. Response to methotrexate treatment is associated with reduced mortality in patients with severe rheumatoid arthritis. Arthritis Rheum 2000;43:14-21.

9 Choi HK, Hernán MA, Seeger JD, Robins JM, Wolfe F. Methotrexate and mortality in patients with rheumatoid arthritis: a prospective study. Lancet 2002;359:1173-7.
10 Okada Y. Proteinases and matrix degradation. In: Ruddy S, Harris ED Sledge CB, eds. Kelley's textbook of rheumatology. 6th ed. Philadelphia: Saunders, 2001:55-72.

11 Feldmann M, Brennan FM, Maini RN. Rheumatoid arthritis. Cell 1996;85:307-10

12 Breedveld FC. Rheumatoid arthritis. In: Smolen JS, Lipsky PE, eds. Targeted therapies in rheumatology. London: Martin Dunitz, 2003:16-17, 502, 590-1

13 Cambridge C, Leandro MJ, Edwards JCW, Ehrenstein R, Salden M, Webster D, et al. B lymphocyte depletion in patients with rheumatoid arthritis: serial studies of immunological parameters [abstract]. Arthritis Rheum 2002;46(suppl):S506

14 Choy EHS, Panayi GS. Cytokine pathways and joint inflammation in rheumatoid arthritis. N Engl J Med 2001;344:164-9.

15 Feldmann M. Development of anti-TNF therapy for rheumatoid arthritis. Nature Rev 2002;2:364-70.

16 Feldmann M, Miotla J, Paleolog E, Williams R, Malfait AM, Taylor P, et al. Future prospects for anti-cytokine treatment. Ann Rheum Dis 2000;59 (suppl I):i1 19-22.

17 Feldmann M, Brennan FM, Maini RN. Role of cytokines in rheumatoid arthritis. Annu Rev Immunol 1996;14:397-440.

17a Neidhart M, Rethage J, Kuchen S, Kunzler P, Crowl RM, Billingham ME, et al. Retrotransposable L1 elements expressed in rheumatoid arthritis synovial tissue: association with genomic DNA hypomethylation and influence on gene expression. Arthritis Rheum 2000;43:2634-47.

18 Aleteha D, Eberl G, Nell VPK, Machold KP, Smolen JS. Practical progress in realisation of early diagnosis and treatment of patients with suspected rheumatoid arthritis: results from two matched questionnaires within three years. Ann Rheum Dis 2002;61:630-4

19 Machold KP, Stamm TA, Eberl GJM, Nell VPK, Dunky A, Uffmann M, et al. Very recent onset arthritis-clinical, laboratory, and radiological findings during the first year of disease. J Rheumatol 2002;29:2278-87.

20 Lard LR, Visser H, Speyer I, vander Horst-Bruinsma IE, Zwinderman AH, Breedveld FC, et al. Early versus delayed treatment in patients with recentonset rheumatoid arthritis: comparison of two cohorts who received different treatment strategies. Am J Med 2001;111:446-51.

21 Nell VPK, Machold KP, Eberl G, Uffmann M, Stamm T, Smolen JS. Benefit of very early referral and therapy with disease-modifying antirheumatic drugs in patients with early rheumatoid arthritis [abstract]. Ann Rheum Dis 2002;61 (suppl I):37

22 Emery P, Breedveld FC, Dougados M, Kalden JR, Schiff MH, Smolen JS. Early referral recommendation for newly diagnosed rheumatoid arthritis: evidencebased development of a clinical guide. Ann Rheum Dis 2002;61:290-7.

23 Aleteha D, Smolen JS. The rheumatoid arthritis patient in the clinic: comparing more than 1,300 consecutive DMARD courses. Rheumatology (Oxford) 2002:41:1367-74.

24 Aleteha D, Smolen JS. Effectiveness profiles and dose dependent retention of traditional disease-modifying antirheumatic drugs for rheumatoid arthritis. An observational study. J Rheumatol 2002;29:1631-8.

25 Boers M, Verhoeven AC, Markusse HM, van de Laar MAFJ, Westhovens R van Denderen JC, et al. Randomised comparison of combined step-down prednisolone, methotrexate and sulphasalazine with sulphasalazine alone in early rheumatoid arthritis. Lancet 1997;350:309-18. 
26 Bathon JM, Martin RW, Fleischmann RM, Tesser JR, Schiff MH, Keystone EC, et al. A comparison of etanercept and methotrexate in patients with early rheumatoid arthritis. N Engl J Med 2000;343:1586-93

27 Genovese MC, Bathon JM, Martin RW, Fleischmann RM, Tesser JR, Schiff MH, et al. Etanercept versus methotrexate in patients with early rheumatoid arthritis: two-year radiographic and clinical outcomes. Arthritis Rheum 2002;46: 1443-50.

28 Matteson EL. Rheumatoid arthritis treatment. In: Klippel JH, Crofford L, Stone $\mathrm{JH}$, Weyand $\mathrm{CM}$, eds. Primer on the rheumatic diseases. 12th ed. Atlanta: The Arthritis Foundation, 2001:225-32.

29 Dougados M, Smolen JS. Pharmacological management of early rheumatoid arthritis - does combination therapy improve outcomes? J Rheumatol 2002;29(suppl 66):20-6

30 Wilder RL. Corticosteroids. In: Klippel JH, Crofford U, Stone JH, Weyand CM eds. Primer on the rheumatic diseases. 12th ed. Atlanta: The Arthritis Foundation, 2001:593-8.

31 O'Dell JR, Haire CE, Erikson N, Drymalski W, Palmer W, Eckhoff J, et al. Treatment of rheumatoid arthritis with methotrexate alone, sulfasalzine and hydroxychloroquine, or a combination of all three medications. N Engl J Med 1996:334:1287-91.

32 Lindqvist E, Saxne T, Geborek P, Eberhardt K. Ten year outcome in a cohort of patients with early rheumatoid arthritis: health status, disease process, and damage. Ann Rheum Dis 2002;61:1055-9.

33 Wolfe F, Zwilich SH. The long-term outcomes of rheumatoid arthritis: a 23year prospective, longitudinal study of total joint replacement and its predictors in 1,600 patients with rheumatoid arthritis. Arthritis Rheum 1998;41:1072-82.

34 Weinblatt ME, Kremer JM, Bankhurst AD, Bulpitt KJ, Fleischmann RM, Fox RI et al. A trial of etanercept, a recombinant tumor necrosis factor receptor:Fc fusion protein, in patients with rheumatoid arthritis receiving methotrexate. N Engl J Med 1999;340:253-9.

35 Lipsky PE, van der Heijde DMFM, St Clair EW, Furst DE, Breedveld FC, Kalden JR, et al. Infliximab and methotrexate in the treatment of rheumatoid arthritis. Anti-Tumor Necrosis Factor Trial in Rheumatoid Arthritis with Concomitant Therapy Study Group. N Engl J Med 2000;343:1594-602.

36 Weinblatt ME, Keystone EC, Furst DE, Moreland LW, Weisman MH, Birbara CA, et al. Adalimumab, a fully human anti-tumor necrosis factor alpha monoclonal antibody, for the treatment of rheumatoid arthritis in patients taking concomitant methotrexate: the ARMADA trial. Arthritis Rheum 2003;48:35-45.

37 Kineret $^{T M}$ (anakinra) package insert. Thousand Oaks, Calif. Amgen Inc;
38 Moreland LW, Schiff MH, Baumgartner SW, Tindall EA, Fleischmann RM Bulpitt KJ, et al. Etanercept therapy in rheumatoid arthritis. A randomized, controlled trial. Ann Intern Med 1999;130:478-86.

39 van de Putte LBA, Atkins C, Malaise M, Sany J, Russell AS, van Riel PCL, et al. Adalimumab (D2E7) monotherapy in the treatment of patients with severely active rheumatoid arthritis [abstract]. Arthritis Rheum 2002;46(suppl):S205.

40 Maini R, St Clair EW, Breedveld F, Furst D, Kalden J, Weisman M, et al. Infliximab (chimeric anti-tumour necrosis factor $\alpha$ monoclonal antibody) versus placebo in rheumatoid arthritis patients receiving concomitant methotrexate: a randomized phase III trial. Lancet 1999;354:1932-9.

41 Moreland LW, Cohen SB, Baumgartner SW, Schiff MH, Tindall EA, Bulpitt KJ, et al. Etanercept (Enbrel) monotherapy for more than 5 years in patients with DMARD-refractory rheumatoid arthritis [abstract]. Arthritis Rheum 2002;46(suppl):S533

42 Breedveld FC, Allaart CF, Rau R, Herborn G, van Riel PLCM, van de Putte LBA, et al. Sustained efficacy over 4 years with adalimumab in patients with active rheumatoid arthritis [abstract]. Ann Rheum Dis 2003;62(suppl I):S169.

43 Landewé $\mathbf{R}$, van der Heijde $D$. Follow up studies in rheumatoid arthritis. Ann Rheum Dis 2002;61:479-81.

44 Remicade $^{\circledR}$ (infliximab) package insert. Malvern, Pa. Centocor, Inc, 2002.

45 Goldsmith CH, Boers M, Bombardier C, Tugwell P. Criteria for clinically important changes in outcomes: development, scoring and evaluation of rheumatoid arthritis patient and trial profiles. J Rheumatol 1993;20:561-5.

46 Kosinski M, Zhao SZ, Dedhiya S, Osterhaus JT, Ware JE. Determining minimally important changes in generic and disease-specific health-related quality of life questionnaires in clinical trials of rheumatoid arthritis. Arthritis Rheum 2000;43:1478-87.

47 Wong JB, Lipsky PE, Maini R, Patel K, van der Heijde D. Rapid radiographic progression in rheumatoid arthritis and clinical and radiographic benefits from infliximab: results from ATTRACT [abstract]. Arthritis Rheum 2002;46(suppl):S337

48 Keystone E, Kavanaugh AF, Sharp J, Hua Y, Teoh L, Fischkoff S, et al. Adalimumab (D2E7), a fully human anti-TNF- $\alpha$ monoclonal antibody, inhibits the progression of structural joint damage in patients with active RA despite concomitant methotrexate therapy [abstract]. Arthritis Rheum 2002;46(suppl):S205

49 FDA. Adalimumab FDA Advisory Panel Briefing Document, March 2003

50 Furst DE, Breedveld FC, Kalden JR, Smolen JS, Antoni CE, Biilsma JWJ, et al. Updated consensus statement on biological agents for the treatment of rheumatoid arthritis and other rheumatic diseases (May 2002). Ann Rheum Dis 2002:61(suppl II):ii2-7. 